\title{
Quantification of Large Deformation with Punching in Dual Phase Steel and Change of its Microstructure -Part I: Proposal of the Quantification Technique of the Punching Damage of the Dual Phase Steel
}

\author{
Tatsuo YOKOI, ${ }^{1) *}$ Hiroshi SHUTO, ${ }^{1)}$ Ken-ichi IKEDA, ${ }^{2)}$ Nobuo NAKADA, ${ }^{3)}$ Toshihiro TSUCHIYAMA, ${ }^{4)}$ \\ Takahito OHMURA, ${ }^{5)}$ Yoji MINE ${ }^{6)}$ and Kazuki TAKASHIMA ${ }^{6)}$
}

1) Oita R \& D Lab. Technical Research \& Development Bureau NIPPON STEEL \& SUMITOMO METAL Corp. 1 Oaza-Nishinosu, Oita City, Oita Pref., 870-0992 Japan. $\quad$ 2) Division of Materials Science and Engineering, Faculty of Engineering, Hokkaido University, Kita13, Nishi8, Kita-ku, Sapporo, Hokkaido, 060-8628 Japan. $\quad 3)$ Department of Materials Science and Engineering, School of Materials and Chemical Technology, Tokyo Institute of Technology, 4259 Nagatsuta-cho, Midoriku,Yokohama, Kanagawa, 226-8503 Japan. $\quad 4$ 4) Department of Materials Science and Engineering, Faculty of Engineering, Kyushu University, 744 Motooka Nishi-ku Fukuoka, 819-0395 Japan. 5) Research Center for Strategic Materials, National Institute for Materials Science, 1-2-1 Sengen, Tsukuba, Ibaraki, 305-0047 Japan. 6) Department of Materials Science and Engineering, Kumamoto University, 2-39-1 Kurokami, Chuo-ku, Kumamoto, 860-8555 Japan.

(Received on May 31, 2016; accepted on July 13, 2016; originally published in Tetsu-to-Hagané, Vol. 102, 2016, No. 5, pp. 244-252)

\begin{abstract}
Dual Phase (DP) steel is used in automotive body parts for weight saving and crashworthiness, however there is an issue of DP steel in low stretch flange ability evaluated by hole expanding tests. In order to improve stretch flange ability of DP steel, it is important to estimate the damage of punching quantitatively and to clarify the change of microstructure before and after punching because the hole expansion ratio is decided in the ductility remained after pre-strain equivalent to punching. Therefore we tried to measure the damage of punching by unique techniques of Electron Backscatter Diffraction (EBSD), nano-indentation and micro-tensile testing and to observe fracture surface by Scanning Transmission Electron Microscope (STEM). Average EBSD-Kernel Average Misorientation (KAM) value and pre-strain damage have strong correlation, thus average KAM value can become the index of the damage. The nanohardness and tensile strength using micrometer-sized specimens increased with increasing average KAM value in the ferritic phase as approaching the punching edge. A shear type fracture occurred without necking in the specimen cut out in the area of the edge. The ultrafine-grained ferritic microstructure was observed in the sample cut out in the same area with STEM. It seems that the ductility loss of the punched DP steel was probably attributed to localized strain into the ultrafine-grained ferritic microstructure.
\end{abstract}

KEY WORDS: dual-phase steel; hole expansion test; electron backscatter diffraction; nano indentation; local strain mapping; strain distribution; micromechanical characterization; strain localization; grain refinement; shear fracture.

\section{Introduction}

In recent years, there has been increasing demand to reduce automobile $\mathrm{CO}_{2}$ emissions by improving their fuel mileage from the viewpoint of protecting the global environment. This has led to calls to reduce car body weight as well as to improve engine characteristics and reduce engine friction. On the other hand, attempts to increase body strength and improve crashworthiness from the viewpoint of occupant protection in crash accidents have been made in the two areas of body structure optimization and body material strengthening. Gauge reduction and strength increase of

\footnotetext{
* Corresponding author: E-mail: yokoi.47n.tatsuo@jp.nssmc.com DOI: http://dx.doi.org/10.2355/isijinternational.ISIJINT-2016-312
}

steel sheets comprising car body members or application of light-gauge and high-strength steel sheets is demanded as a solution to achieving the two contradictory objectives of lower fuel economy and higher crashworthiness. ${ }^{1)}$ However, increasing the strength of steel sheets is generally known to decrease their formability. Minimizing this formability degradation by increasing strength is an important steel development issue. ${ }^{2)}$

Since the late 1970s, research has been conducted on dual-phase (DP) steel with a microstructure composed of soft ferrite and hard martensite as sheet steel that can be strengthened while limiting the degradation of formability to the extent possible. ${ }^{3-7)}$ These research efforts have culminated in the development of high-strength DP steel sheets with a low yield ratio, high work hardening rate, room- 
temperature non-aging property, high bake hardenability, ${ }^{8,9)}$ and excellent fatigue properties. ${ }^{10)}$ After the mid-1990s when the Japan New Car Assessment Program (JNCAP) was initiated to evaluate the crashworthiness of cars, these high-strength sheet steels rapidly replaced mild steels as materials for frame structural members to ensure crashworthiness. More recent years have seen the demand increasing for advanced high strength steel (AHSS) with a tensile strength of over $1 \mathrm{GPa}^{\left.1{ }^{11}\right)}$ These frame structural members of automobiles must be formed from high-strength steels into complex shapes to perform as required. How to ensure stretch flangeability has become an issue not encountered with lower-strength steels so far. ${ }^{12)}$

Stretch flangeability is generally evaluated by the limiting the hole expansion ratio determined by the hole expanding test. The hole expanding test is a test method to evaluate stretch flangeability. It was established as a Japan Iron and Steel Federation Standard ${ }^{13)}$ and later adopted as JIS Standard Z 2256 ${ }^{14)}$ and ISO Standard $16630 .^{15)}$ The limiting hole expansion ratio is the degree of hole expansion obtained in a circular punched hole of a test specimen when a conical punch is forced into the hole until any one crack in the hole edge extends through the specimen thickness. It is expressed as the ratio of hole diameter expansion to the original hole diameter. ${ }^{14)}$ This test method is characteristic in that it can evaluate stretch flangeability as done on presses in mass-production shops. The hole expanding test simulates two continuous steps: punching equivalent to blanking on the press, and hole expansion equivalent to stretch flanging on the press. It is an industrially very useful evaluation technique.

The two-step nature of the hole expanding test complicates the relationship between the limiting hole expansion ratio and mechanical properties of specific materials and hinder the understanding of the phenomena involved. In other words, the hole expanding test is such a technique whereby deformability after the pre-strain or damage in the punching step is evaluated in the subsequent hole expansion step. The limiting hole expansion ratio can be interpreted as an evaluation value of deformability after the punching damage has occurred. The effects of punching damage on the behavior of the crack propagating from the hole edge in the thickness direction through metallurgical changes such as dislocation structure and microstructure are unknown in many respects.

Takahashi et al. ${ }^{16)}$ observed in detail the behavior of the crack initiated at the hole edge and propagating from the hole edge as a factor controlling punched hole expandability. They clarified the fact that most of the phenomena occurring in the hole expanding test are due to the propagation, but not the initiation, of the cracks. They also discussed the hypothesis that a major factor governing the limiting hole expansion ratio is not crack propagation in a damaged region introduced near the hole edge in the punching step but rapid crack propagation in a region relatively far from the hole edge where the punching damage disappears. They reported that the limiting hole expansion ratio is determined by crack propagation resistance where there is no punching damage or by the crack propagation resistance, Jmat, of the matrix.

Takahashi et al. ${ }^{17)}$ measured the crack propagation resistance of the matrix and pre-strained specimens of DP steel and precipitation-hardening steel. They indicated that the crack propagation resistance, Jmat, of the matrix was lower for DP steel than for precipitation-hardening steel and that the decrease in crack propagation resistance, Jmat, with pre-straining was larger for DP steel than for precipitationhardening steel. They observed crack cross sections and fracture surfaces and estimated that the main cause of the lower crack propagation resistance, Jmat, of DP steel was the fracture of hard martensite ahead of the crack tip or void initiation and linkage due to interfacial separation between ferrite and martensite. They further developed a punched limiting hole expansion ratio prediction model by considering the punching damage distributed in the radial direction from the punched hole edge and by using the crack propagation resistance, Jmat, and crack driving force, Japp, of the matrix. ${ }^{18)}$

Concerning the void formation that Takahashi et al. estimated to be the main cause of reduction in crack propagation resistance of DP steel, attempts are made to investigate in detail its relationship to such microstructural factors as the volume fraction of martensite, grain size of martensite and ferrite, strength of martensite, and formation and distribution of martensite and to explain the ductile fracture behavior of DP steels. ${ }^{19-23)}$ These researches, however, did not consider the damage done by pre-straining equivalent to punching and did not provide clear guidelines for improving the stretch flangeability of DP steel, which may become a problem during pressworking in mass-production shops.

To understand the ductile fracture phenomenon of DP steel in the hole expanding test, in the present study, we performed punched hole specimens to simulate the punched hole expanding test and observed the fracture surfaces of punched hole specimens after the tensile test. Next, we quantified the punching damage by using electron backscatter diffraction (EBSD) and other techniques, performed nano-hardness measurements, and examined microstructural changes by electron microscopy. Furthermore, we cut out micro-tensile test specimens near the punched hole edge and directly measured the mechanical properties of the damaged region. We comprehensively interpreted the obtained results and tried to understand the punched hole expansion mechanism of DP steel from a metallurgical point of view.

To understand the punched hole expansion mechanism of DP steel from a metallurgical point of view, this report quantifies punching damage by using a cold-rolled DP steel with a tensile strength of $590 \mathrm{MPa}$ as the test material, verifies the validity of the mechanical property measurement techniques employed, assumes the crack produced in hole expansion to be ductile fracture, and proposes its mechanism.

\section{Experimental Methods}

\subsection{Test Material}

A dual-phase steel whose chemical composition is shown in Table 1 was melted as the test material. It was then cast,

Table 1. Chemical composition of the steel studied (mass\%).

\begin{tabular}{cccccccc}
\hline $\mathrm{C}$ & $\mathrm{Si}$ & $\mathrm{Mn}$ & $\mathrm{P}$ & $\mathrm{S}$ & $\mathrm{Al}$ & $\mathrm{N}$ & $\mathrm{Fe}$ \\
\hline 0.072 & 0.45 & 1.86 & 0.010 & 0.0026 & 0.023 & 0.0034 & Bal. \\
\hline
\end{tabular}


hot rolled, cold rolled to a thickness of $1.2 \mathrm{~mm}$, heated to $1073 \mathrm{~K}$ or a ferrite-austenite two-phase region temperature, and cooled to a ferrite-martensite microstructure. Figure 1 shows optical micrographs of cross sections of the test material parallel to the rolling direction and after nital and Le Pera etching, respectively. The test material exhibits microstructures typical of cold-rolled DP steel with a 590-MPa-grade tensile strength. These microstructures are characteristic in that martensite grains, a few micrometers in size, are connected like a chain of beads along the boundaries of ferrite grains, about $10 \mu \mathrm{m}$ in size. This is probably because ferrite grain boundaries act as nucleation sites when ferrite reversely transforms to austenite after recrystallization during heat treatment in the ferrite-austenite two-phase temperature region after cold rolling. The area fraction of martensite is about $8 \%$.

JIS No. 5 test specimens were taken to orient their longitudinal direction in the transverse direction of the test steel sheet and were tested as specified in JIS Z 2241: 2011. The hole expanding test was performed as specified in JIS $\mathrm{Z}$ 2256: 2010. The die-punch clearance was changed from $5.8 \%$ through $12.5 \%$ to $20.8 \%$. Drilled hole specimens were also tested. The mechanical properties of the steel are shown in Table 2. The mechanical properties obtained are those of a DP steel of 590-MPa grade with a low yield ratio and an excellent strength-ductility balance.

\subsection{Punching and Specimen Sampling}

The punched hole expansion ratio is known to change with the die-punch clearance. In the present study, we prepared punched hole specimens by changing the clearance as required to change the damage due to punching. Some specimens had holes drilled. Figure 2 schematically illustrates hole punching and subsequent testing procedures. Specimens with a hole punched at the center were tensile tested to simulate the hole expanding test. A strain gradient is known to occur in the radial direction in the hole expanding test. ${ }^{25)}$ The punched hole specimen tensile test cannot completely simulate the hole expanding test, but we thought that the test could achieve the purpose of evaluating the effect of punching damage on the fracture morphology.

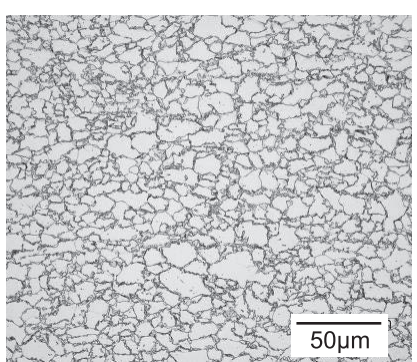

(a)Nital etching

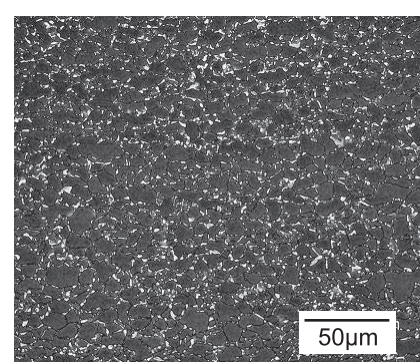

(b)Le Pera etching
Fig. 1. Micro-structure of the steel studied.

Table 2. Mechanical properties of the steel studied.

\begin{tabular}{|c|c|c|c|c|c|c|}
\hline \multirow{2}{*}{$\begin{array}{l}\text { Yield } \\
\text { stress } \\
(\mathrm{MPa})\end{array}$} & \multirow{2}{*}{$\begin{array}{c}\text { Tensile } \\
\text { strength } \\
(\mathrm{MPa})\end{array}$} & \multirow{2}{*}{$\begin{array}{l}\text { Elongation } \\
\quad(\%)\end{array}$} & \multicolumn{4}{|c|}{ Hole expansion ratio (\%) } \\
\hline & & & Machined & $\mathrm{CL}=5.8 \%$ & $\mathrm{CL}=12.5 \%$ & $\mathrm{CL}=20.8 \%$ \\
\hline 384 & 640 & 29.2 & $>250$ & 46 & 64 & 60 \\
\hline
\end{tabular}

The next step was the measurement to quantify the punching damage. The specimens for this purpose were sampled from the positions shown in Fig. 3. Of the clearances of 5.8 to $20.8 \%$ with which the holes were punched in the specimens, the burnish zone ratio was smallest with a clearance of $20.8 \%$. The punched hole edge in the $300-\mu \mathrm{m}$-thickness position from the specimen surface was not a fracture zone but a burnish zone. The items investigated in these sampling positions are shown in Table 3. The scanning electron microscopy-electron backscatter diffraction (SEM-EBSD) technique continuously measured not only the regions in positions (4) and (2) very near the burnish zone and fracture zone, respectively, of the punched hole edge shown in Fig. 3 , but also the region at $500 \mu \mathrm{m}$ in the radial direction and $300 \mu \mathrm{m}$ in the thickness direction. The confidence index (CI) that indicates the reliability of EBSD data very near the burnish zone was low. EBSD data with a CI of 0.2 or less were not adopted.

\subsection{Tensile Test and Fracture Surface Observation of Punched Hole Specimens}

The punched hole tensile test specimens were 100-mmlong and $30-\mathrm{mm}$-wide strip specimens with the tension axis oriented in the rolling direction. These specimens each had

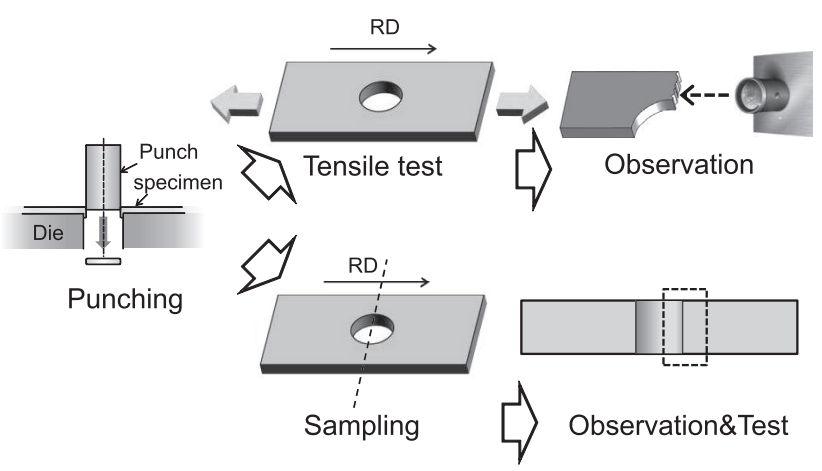

Fig. 2. Experimental procedure.

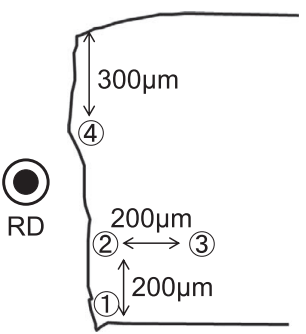

Fig. 3. Position of observation to SEM and S-TEM and tests.

Table 3. Measurement and testing position of specimens.

\begin{tabular}{ccccc}
\hline & $\begin{array}{c}\text { Nano } \\
\text { indentation }\end{array}$ & $\begin{array}{c}\text { Micro- } \\
\text { tensile test }\end{array}$ & SEM-EBSD & STEM \\
\hline Matrix & $\bigcirc$ & $\bigcirc$ & $\bigcirc$ & $\bigcirc$ \\
Position(1) & $\bigcirc$ & - & - & - \\
Position(2) & $\bigcirc$ & $\bigcirc$ & $\bigcirc$ & - \\
Position(3) & $\bigcirc$ & $\bigcirc$ & - & - \\
Position(4) & $\bigcirc$ & $\bigcirc$ & $\bigcirc$ & $\bigcirc$ \\
\hline
\end{tabular}


a hole punched at the center with a $10 \mathrm{~mm} \phi$ punch and a $12.5 \%$ clearance. The tensile test was conducted at a tension rate of $1 \mathrm{~mm} / \mathrm{min}$. A crack propagated in the direction perpendicular to the tension axis of the punched hole edge where stress was concentrated and eventually led to a fracture.

To observe the fracture zone near the hole edge of the specimens fractured in the tensile test, fractography specimens were prepared from some of the broken tensile test specimens and secondary electron images of their fracture zones were taken by using a Hitachi High-Technologies Model S-3000H scanning electron microscope (SEM) with an accelerating voltage of $25 \mathrm{kV}$ and an operating distance of 9 to $11 \mathrm{~mm}$.

\subsection{SEM, EBSD, and S-TEM Observation}

SEM-EBSD measurement and analysis were performed to quantify the damage induced by punching. Microscopy specimens were cut out from the tensile test specimen cross sections normal to the rolling direction and punching direction and were investigated. Attention was focused on the upper burnish zone and lower fracture zone in the punching direction. Microstructural observation and grain orientation analysis were conducted for regions (1) to (4) shown in Fig. 3 . The specimens used for these observations had their holes punched with a die-punch clearance of $5.8 \%$ or $20.8 \%$. They were mechanically polished, chemically etched, and buffed with colloidal silica. Microstructural observations with secondary electron images and backscattered electron images were performed by using a Carl Zeiss ULTRA 55 field-emission scanning electron microscope (FE-SEM). The grain orientations of the specimens near the burnish zone and fracture zone in positions (4) and (2), respectively, were analyzed using the EBSD method with an accelerating voltage of $20 \mathrm{kV}$, an operating distance of $15 \mathrm{~mm}$, and an analytical spacing of $0.5 \mu \mathrm{m}$. Since the grain size of martensite was fine in the DP steel used in the present study, we assumed that the grains that could be analyzed were only those of ferrite. The dislocation structures of the matrix and punched hole region were compared by scanning transmission electron microscopy (S-TEM). Matrix specimens were taken from regions far from the punched hole edge, thinned by mechanical polishing, and argon ion milled to obtain thin-film specimens. Punched hole region specimens were taken from the normal direction (ND) section near the fracture zone and thinned by a focused ion beam (FIB) system to prepare thin-film specimens. The S-TEM observation of the thin-film specimens was performed with a JEOL Model JEM-2100 transmission electron microscope with an accelerating voltage of $200 \mathrm{kV}$.

\subsection{Nano-hardness Measurement of the Punched Hole Region}

To quantify the punching damage, nano-hardness was measured in positions (1) to (4) shown in Fig. 3. In particular, the nano-hardness test is expected not only to measure the nano-hardness of ferrite and martensite, but also to distinguish ferrite and martensite in the punched hole region. The nano-hardness test was performed with a Berkovich diamond pyramid indenter on specimen surfaces finally finished by electrolytic polishing. The Oliver-Pharr method was used to calculate the nano-hardness, Hn, from the loaddisplacement curve. The specimen surface was observed with a scanning probe microscope, the microstructural morphology was examined to distinguish between ferrite and martensite, and the nano-hardness measurement positions were selected accordingly.

\subsection{Micro-tensile Test of Specimens Cut Out from the Punched Hole Region}

Micro-tensile test specimens were sampled from the punched hole region positions shown in Fig. 3. A portion was cut out from the punched hole region with a fine cutter and mechanically polished to arrive at the desired section. The tension direction of the micro-tensile test specimen is parallel to the rolling direction of the test material. The specimen was then focused ion beam milled by an FEI Quanta 3D system to the geometry shown in Fig. $\mathbf{4}$ and specified in JIS C 5630-2. The micro-tensile test was performed at room temperature in air and at a displacement rate of $0.1 \mu \mathrm{m} / \mathrm{sec}$.

The micro-tensile testing machine employed in this test uses a piezoelectric device as an actuator to apply load to the specimen and has a loading jig attached to the end of the actuator. ${ }^{26)}$ The specimen holder and loading mechanism are attached to the loading jig and mounted on precision X-Y-Z stages and a rotary stage with a positioning repeatability of $0.1 \mu \mathrm{m}$. This setup can position the specimen with high accuracy. The testing apparatus is equipped with a white light interferometer capable of measuring the specimen surface geometry with a resolution of $0.2 \mathrm{~nm}$. It can thus measure the strain of the specimen as well as the surface profile accompanying the deformation of the specimen surface. ${ }^{27)}$ The fracture surfaces of fractured micro-tensile test specimens were observed with a JEOL Model JSM-5600 scanning electron microscope at an accelerating voltage of $15 \mathrm{kV}$ to examine their fracture morphology.

\section{Results and Discussion}

\subsection{Change of Fracture Morphology with Punching}

Figure 5 shows SEM micrographs of the fracture surface of a punched hole specimen fractured in the tensile test. The fracture surface far from the punched hole edge reveals a dimpled fracture surface similar to the fracture surface of a normal tensile test specimen. A dimpled fracture surface similar to the fracture surface far from the punched hole edge was not observed at the same magnification in the area extremely close to the punched hole edge. Observed

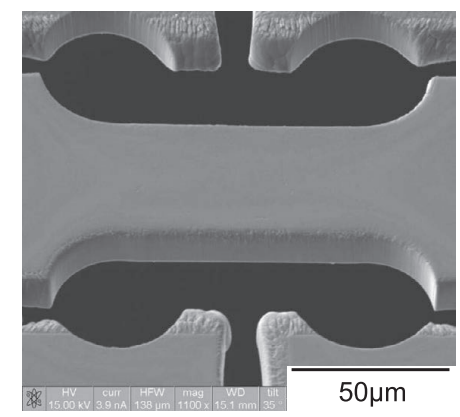

Fig. 4. SEM micrographs of Micro-tensile test specimen shaped by FIB. 
instead is a relatively flat fracture surface and a fracture surface where relatively small dimples are sparsely present. Generally, ductile fracture is understood to occur as microvoids initiate at inclusions and second-phase particles and within and between the grains in the material, which then grow and eventually coalesce. Primary dimples corresponding to voids are observed on the fracture surfaces of materials fractured in this way. ${ }^{28)}$ This is considered to be one characteristic of ductile fracture. In DP steel, voids are considered to originate from martensite and correspond to primary dimples. The amount of applied strain expended in the growth of voids is small in DP steel with a second phase of martensite, as observed on the relatively flat fracture surface extremely close to the punched hole edge and the fracture surface with presence of relatively small dimples. This is regarded as a rare case of voids coalescing as soon as they are formed and eventually leading to fracture. The change in the inside of the material due to punching is suggested to be a direct cause.

\subsection{Quantification of Punching Damage}

The kernel average misorientation (KAM) value used to quantify the local misorientations within the grains are considered to reflect the amount of geometrically necessary (GN) dislocations accumulated within the grains. ${ }^{29)}$ Based on this consideration, attempts are made to quantify the amount of plastic deformation of materials by the KAM value. $^{30)}$ Our present study also attempted to treat the

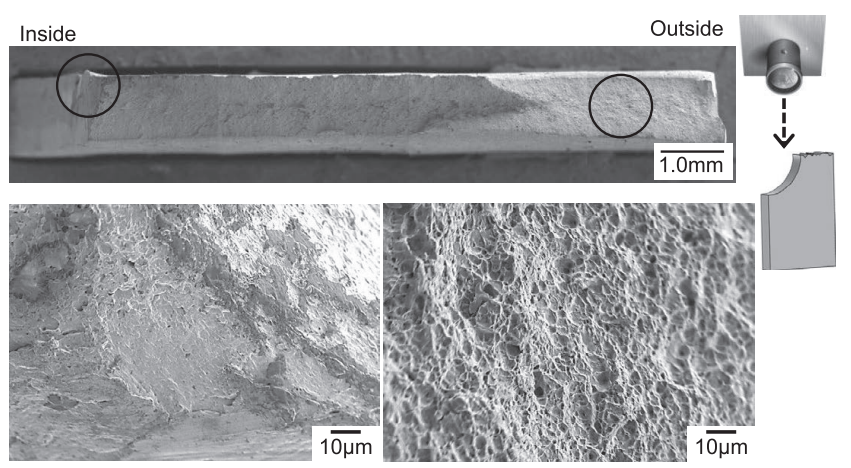

Fig. 5. SEM micrographs of the fracture surface on the punched specimen $(\mathrm{CL}=12.5 \%)$.

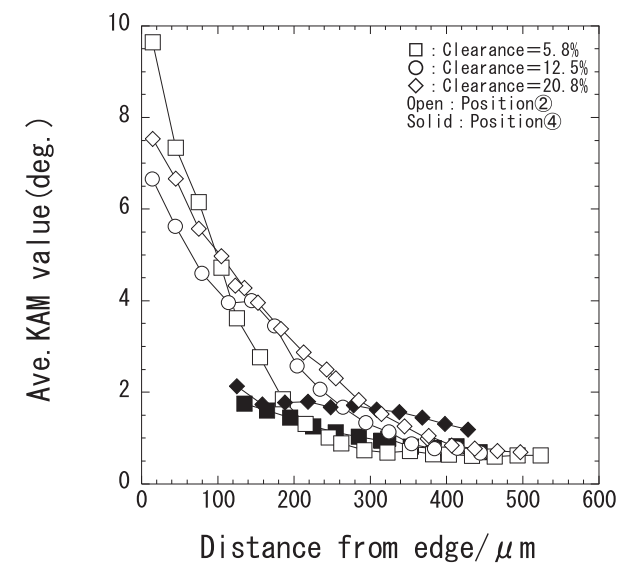

Fig. 6. Relationship between distance from fractured edge and Average KAM value. damage introduced by the hole punching operation as the amount of plastic deformation.

The relationship between the distance from the punched hole edge and the average KAM value is shown in Fig. 6. The average KAM values obtained by the EBSD analysis of rectangular regions with a width of $30 \mu \mathrm{m}$ in the radial direction of the punched hole and a depth of $300 \mu \mathrm{m}$ in the thickness direction by reference to the punched hole edge is plotted as average KAM value against the distance of the center position of the rectangular regions from the punched hole edge. Our present study calculated the KAM values by analyzing the grain orientations with the grain orientation analysis software TSL Solutions OIM Analysis Version 7.1.0. The EBSD-KAM values were calculated by the average misorientations between the measurement point and the six first proximate points adjoining the measurement point and by adopting misorientations of $10^{\circ}$ or more. The average KAM values decrease as the distance from the punched hole edge increases and converge to $1^{\circ}$ or less at distances of more than $300 \mu \mathrm{m}$. The average KAM values in the punched hole edge and the distribution of the average KAM values in the radial direction change with the die-punch clearance. The limiting hole expansion ratio also changes with the diepunch clearance. The average KAM value is thus considered to be effective as an index for quantitatively evaluating the damage introduced by the hole punching operation.

\subsection{Nano-hardness Measurement of Microstructures in Punching-damaged Regions}

Figure 7 shows scanning probe microscope (SPM) micrographs of nano-hardness measurement positions. In the positions near the punched hole edge, except position (3), the amount of plastic deformation is very large so that it appears difficult to distinguish between ferrite and martensite. In the positions extremely close to the punched hole edge or positions (1), (2), and (4) as compared with the position further from the punched hole edge or position (3),

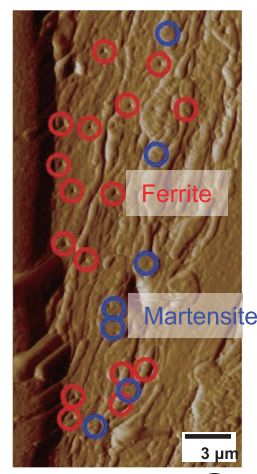

(a)Position(2)

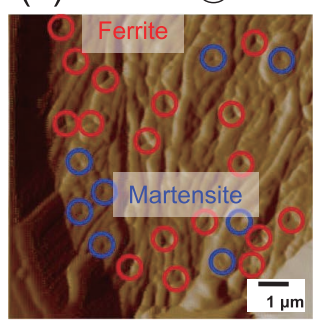

(c)Position (1)

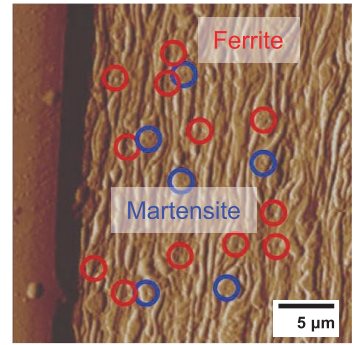

(b)Position (4)

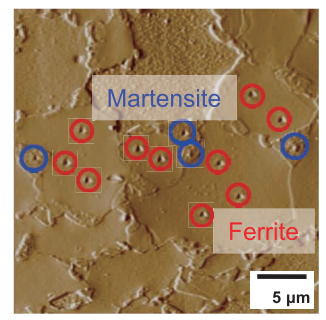

(d)Position(3)
Fig. 7. SPM images of the cross section indented $(\mathrm{CL}=5.8 \%)$. 
not only ferrite but also martensite is deformed, and the martensite grains appear to have lost their original shape. In positions (1), (2), and (4), therefore, it was difficult to measure the hardness of ferrite and martensite separately. After the nano-hardness measurement, ferrite and martensite were classified according to the measured nano-hardness values.

Table 4 shows the measured nano-hardness values. In the matrix not affected by the hole punching operation, the nano-hardness of ferrite is about $4 \mathrm{GPa}$. The nano-hardness of martensite varies greatly but is averaged at about 14 GPa. This means that the grains with a nano-hardness of 8.5 $\mathrm{GPa}$ or more can be recognized as those of martensite. In positions (1), (2), and (4), on the other hand, the average nano-hardness of ferrite is about 5.1 to $7.5 \mathrm{GPa}$. These nano-hardness increases may be ascribed to work hardening arising from punching-induced plastic deformation. The nano-hardness of martensite averages 10 to $15.9 \mathrm{GPa}$, and these nano-hardness data vary greatly. The difference in the magnitude of punching damage between the nano-hardness measurement positions is not clear. The nano-hardness changes in these positions are not clear-cut as compared with the matrix.

Concerning the work hardening of as-quenched martensite, Nakajima et $a l .{ }^{31)}$ investigated the changes of an $\mathrm{Fe}-18 \% \mathrm{Ni}$ alloy in yield behavior and dislocation density with pre-straining. They clarified the fact that very slight pre-straining causes movement and pair annihilation of mobile dislocations, decrease in dislocation density, and increase in the elastic limit. From SPM micrographs of the DP steel we investigated, it is observed that both ferrite and martensite are plastically deformed greatly in the positions extremely close to the punched hole edge. From the nanohardness measurements, it is also recognized that the ferrite

Table 4. Measured results of nano indentation.

\begin{tabular}{|c|c|c|c|c|c|c|}
\hline & & & & & & $(\mathrm{GPa})$ \\
\hline & & Position (1) & Position(2) & Position(3) & Position(4) & Matrix \\
\hline \multirow{2}{*}{$\mathrm{CL}=5.8 \%$} & Ferrite & $6.1 / 1.0$ & $5.1 / 0.9$ & $6.0 / 0.6$ & $6.6 / 1.4$ & $4.0 / 0.2$ \\
\hline & Martensite & $12.6 / 1.5$ & $11.2 / 1.5$ & $15.9 / 1.7$ & $10.0 / 1.9$ & $13.8 / 3.5$ \\
\hline \multirow{2}{*}{$\mathrm{CL}=20.8 \%$} & Ferrite & $6.2 / 1.3$ & $6.5 / 1.6$ & $5.6 / 0.8$ & $7.5 / 1.0$ & - \\
\hline & Martensite & - & $12.0 / 2.3$ & $13.6 / 1.8$ & $11.9 / 1.3$ & - \\
\hline
\end{tabular}

(Average/Standard deviation)

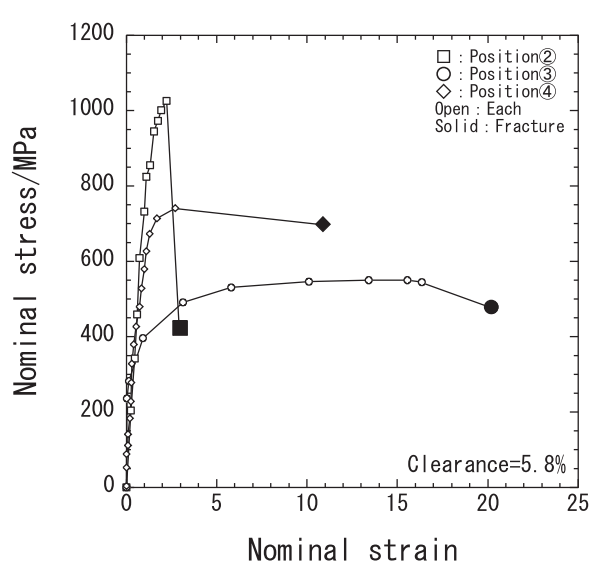

is work hardened. However, no change in elastic limit can be identified from the nano-hardness measurement. At least, no clear tendency was observed for the work hardening of martensite.

\subsection{Measurement of Mechanical Properties in Punching- damaged Regions by the Micro-tensile Test}

Figure 8 shows the stress-strain curves of micro-tensile test specimens taken from positions (2), (3), and (4). The strain on the $\mathrm{x}$ axis of the graph is the strain measured with a white light interferometer using a digital image correlation technique (DIC). The y axis plots the nominal stress or the load measured with a load cell and divided by the initial specimen cross-sectional area. As compared with the stress-strain curves of the specimens at the matrix and position (3), the fracture strain of the specimens at positions (2) and (4) decreases with increasing tensile strength. In other words, the mechanical properties of these specimens are greatly different from those of the specimens at the matrix and position (3). These stress-strain curves indicate the nominal strain estimated with the white light interferometer and the nominal stress automatically acquired from the load cell measurements during the micro-tensile test. Since the final point acquisition timing and strain rate vary with the specimen, the strain at the final point is not fracture strain obtained from what is called fracture elongation. The shapes of the stress-strain curves vary according to the die-punch clearance and according to whether the specimens were at the burnish zone or fracture zone of the punched hole edge. The reason for this variation cannot be explained by the KAM values near the punched hole edge. Probably, these curve shapes are greatly affected by the relationship between the grain orientation and tension direction of the evaluated micro-tensile test specimens, the volume fraction of ferrite grains and martensite grains, the relationship between the ferrite/martensite interface and tension direction, and the constraint conditions for the ferrite and martensite grains.

Figure 9 shows SEM fracture surface micrographs of the micro-tensile test specimens after the test. The specimens at the matrix and position (3) exhibit chisel-point fracture surfaces, while the specimens at positions (2) and (4) exhibit shear or cup-and-cone fracture surfaces. This is probably because the specimens at positions (2) and (4) were lower in ductility than the specimens at the matrix and position

Fig. 8. Nominal stress-strain curves by micro-tensile test.

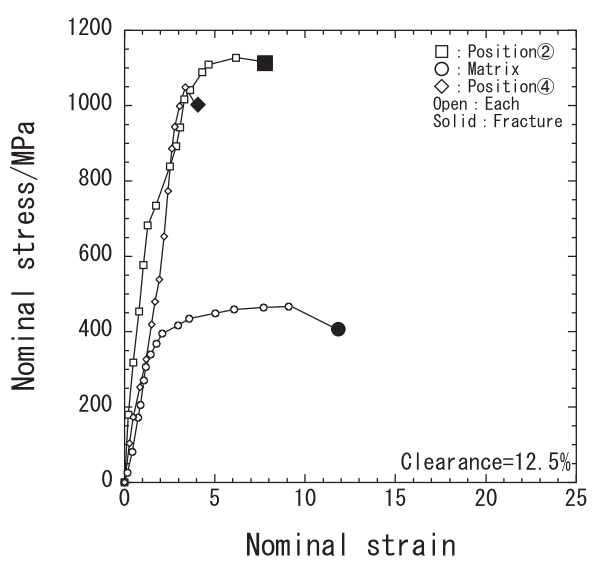


(3) and failed before they fully necked. When the fracture surfaces are examined in detail, dimples are observed on the fracture surfaces of some of the specimens at positions (2) and (4), as compared with the specimens at the matrix and position (3). The observed dimples are very small in size, about a few micrometers, as compared with the dimples observed in the matrix of the punched hole tensile test specimens of normal size. The latter dimples are about 10 $\mu \mathrm{m}$ and equivalent to the ferrite grains in size.

In this way, the micro-tensile test specimens at the matrix and position (3) are greatly different in fracture morphology and fracture surface appearance from the micro-tensile test specimens from positions (2) and (4). With DP steel, it is generally recognized that voids initiate from martensite, then grow and coalesce, and ultimately lead to ductile fracture. The possibility is suggested of this ductile fracture process having changed into a process of initiated voids instantly coalescing and leading to fracture, with a lower percentage of the punching pre-strain spent in void growth.

\subsection{S-TEM Observation of Dislocation Structure in Punching-damaged Regions}

Figure 10 shows bright-field (BF) S-TEM micrographs of the specimens from the matrix and from position (4). Highdislocation-density martensite grains are observed to surround low-dislocation-density ferrite grains in the specimen from the matrix. As shown in the optical micrographs of
Fig. 1, the ferrite grains are about $10 \mu \mathrm{m}$ and the surrounding martensite grains are a few micrometers in size. The grains observed in the specimen from position (4) are subgrains, and these subgrains are mostly $1 \mu \mathrm{m}$ or less in size.

This is very similar to the ultrafine-grained microstructure obtained by applying severe plastic deformation, 4 to 5 times larger than equivalent plastic strain, to a bulk material. ${ }^{32)}$ Ultrafine-grained steels are known to be excellent in strength reduction of area balance but low in uniform elongation. $^{33,34)}$ Reduction of uniform elongation by the formation of an ultrafine-grained microstructure is considered to be a factor in the reduction of ductility of the micro-tensile test specimen from position (4).

Okitsu et al. ${ }^{35,36)}$ report that when a DP steel is cold rolled and optimally heat treated, an ultrafine-grained microstructure is obtained where fine cementite is dispersed in ferrite. They also say that an ultrafine-grained microstructure is evolved in DP steel with an equivalent plastic strain smaller than the severe plastic deformation claimed to produce finegrained steels.

Namely, the ultrafine-grained microstructure in the ferrite of DP steel is hard to deform in plastic, therefore it seems that this microstructure fractures at the low plastic strain corresponding to the hole expanding test. The formation process of the ductile fracture after the deformation limit can be assumed from the relatively flat fracture surface with a sparse presence of relatively small dimples as shown in the
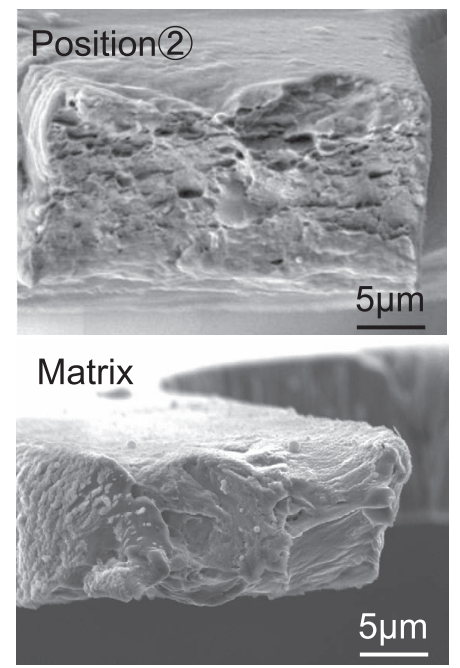
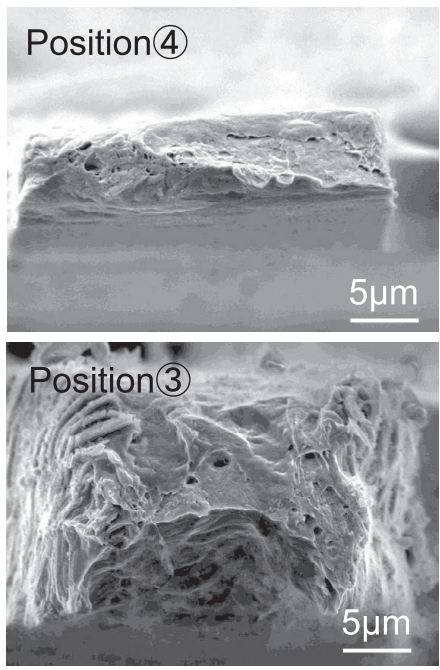

Fig. 9. SEM micrographs of fracture surface on micro-tensile specimens $(\mathrm{CL}=5.8 \%)$.
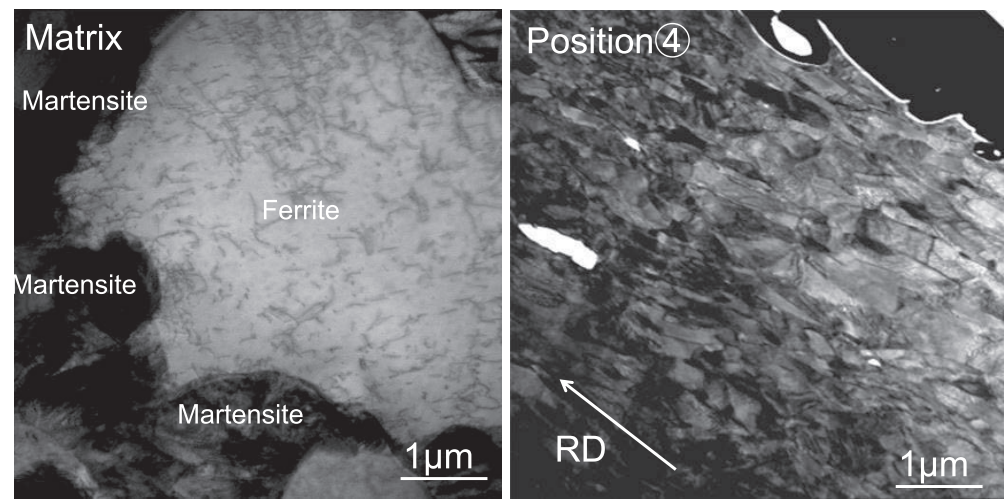

Fig. 10. Bright-field STEM micrographs in differ and near from fracture edge $(C L=12.5 \%)$. 
SEM micrographs of Figs. 5 and 9. A hypothesis can be thus derived that the general ductile fracture process comprising void initiation, growth, and coalescence has changed into a process in which a small amount of strain is expended in void growth and the initiated voids easily coalesce.

Unless the equivalent plastic strain introduced by the hole punching operation near the punched hole edge is quantitatively grasped, it cannot be demonstrated that the hole punching operation does not form an ultrafine-grained microstructure in homogeneous steel but yields an ultrafinegrained microstructure in DP steel. The damage (equivalent plastic strain) due to the hole punching operation has a gradient with the distance in the radial direction or the position in the thickness direction from the punched hole edge. Even if the equivalent plastic strain in a given position can be quantitatively grasped, it is very difficult to relate the equivalent plastic strain to the mechanical properties of the material in that position. In our next report, we will conduct our study by using (1) specimens with different microstructures to clarify microstructural factors and (2) a strain introduction technique that can control the resultant damage. Our main research objective will be to quantitatively grasp the relationship between the introduced equivalent plastic strain and microstructure in order to understand the ductile fracture phenomenon in the hole expanding test of DP steel from a metallurgical point of view.

\subsection{Relationship between Punching Damage and Mechanical Properties}

Figure 11 shows the relationship of the average KAM value with the nano-hardness and the tensile strength obtained from the micro-tensile test. The error bars denote standard deviations. The plotted points indicate the average KAM value and micro-tensile strength in the same positions as the nano-hardness measurement positions shown in Table 4. The nano-hardness and micro-tensile strength are organized by the average KAM value. As described earlier, the KAM value is considered to reflect the amount of GN dislocations accumulated within the grains and to correspond to the equivalent plastic strain. The relationship between the average KAM value and equivalent plastic strain is not necessarily linear. However, there is observed a tendency for micro-tensile strength and ferrite nano-hardness to

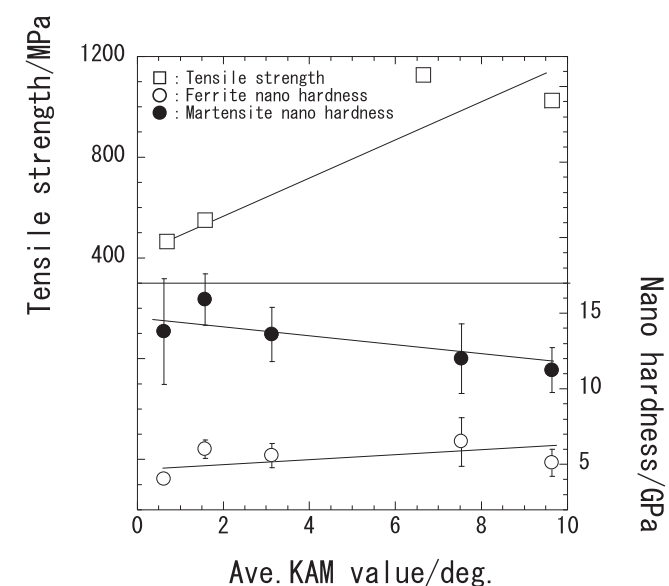

Fig. 11. Relationship between Ave. KAM value and Nano hardness, Micro-tensile strength. increase with increasing average KAM value. In particular, tensile strength is generally inversely correlated with fracture elongation. As far as residual ductility after the hole punching operation is concerned, the tensile strength from the micro-tensile test is strongly correlated with the punched hole expansion ratio. The average KAM value thus can be used an index for quantitatively evaluating the damage due to the hole punching operation.

On the other hand, there is seen a tendency for the nanohardness of martensite to decrease with increasing average KAM value. The SPM micrographs show that the martensite grains are also plastically deformed very greatly near the punched hole edge. This decrease in nano-hardness of martensite with the increase in average KAM value appears to be due to work softening accompanying the plastic deformation of martensite. Tamura et al. report the work softening phenomena of $\mathrm{Fe}-\mathrm{Ni}-\mathrm{C}$ martensites. ${ }^{37,38)}$ When martensite having transformation twins is worked, low-carbon martensite deforms by slip and high-carbon martensite deforms by twinning. Work softening is shown to arise from the annihilation of transformation twins. We have not confirmed that many transformation twins are contained in the martensite grains comprising the DP steel investigated in our present study. There exists the possibility that many twins are contained due to martensite transformation by lattice invariant shear when the martensite grains are surrounded and constrained by ferrite grains.

\section{Conclusions}

To understand the ductile fracture phenomena in the hole expanding test of DP steel, our present study performed quantification of punching damage with the aid of EBSD and other techniques. We then performed the punched hole specimen tensile test to simulate the punched hole expanding test, observed the fracture surfaces of specimens taken near the punched hole edge, measured the nano-hardness of the specimens, and measured the microstructural changes of the specimens by electron microscopy. Furthermore, we cut out micro-tensile test specimens from the punched hole regions and directly measured the mechanical properties of the regions damaged by the hole punching operation. As a result, the following findings were obtained:

(1) The fracture zone of the punched hole edge in the DP steel was different from a general dimpled fracture surface. This tendency agreed with the tendency of the microtensile test of specimens cut out from very near the punched hole edge. The amount of the strain expended in the growth of voids was small. The possibility was suggested that the initiated voids could immediately coalesce and eventually lead to fracture.

(2) The results of the micro-tensile test clarified that the ferrite grains near the punched hole edge were severely work hardened and decreased in ductility.

(3) The possibility was indicated of quantitative interpretation of the strain distribution by the EBSD-KAM method. Consequently, it was indicated that the strain was high near the punched hole edge and decreased with increasing distance in the radial direction from the punched hole edge.

(4) From the nano-hardness measurements, it was 
recognized that the nano-hardness of the martensite grains increased near the punched hole edge, but that the nanohardness of the ferrite grains markedly increased near the punched hole edge.

(5) The S-TEM micrographs of the specimens from very near the punched hole edge show that the ferrite grains were subgrains and mostly $1 \mu \mathrm{m}$ or less in size. This suggested the formation of ultrafine ferrite grains. Namely, the adoption of EBSD-KAM values and the measurement of nano-hardness to support the validity of EBSD-KAM value adoption were found to be effective in quantitatively grasping the hole punching damage. The cause of the lower punched hole expandability of DP steel as compared with precipitation-hardening steel, for example, was estimated as follows. The ferrite grains in the dual-phase microstructure are soft by their nature. When DP steel is punched with a hole, the hole punching damage is concentrated in the ferrite grains and a fine-grained microstructure is formed in the ferrite grains with an equivalent plastic strain much smaller on average than the equivalent plastic strain applied to obtain an ultrafine-grained microstructure from a homogeneous bulk steel. The plastic deformability is greatly reduced and a small amount of the strain is expended in void growth. The initiated voids promptly coalesce and eventually lead to fracture.

To verify this estimate, however, it is necessary to create an index for expressing the hole punching damage as the amount of plastic deformation more directly than the KAM value and to develop a technique for measuring the index; to establish techniques for applying a given plastic deformation to specimens with good reproducibility and evaluating the mechanical properties of the specimens; and to clarify the fracture mechanism of the ultrafine-grained microstructure formed in the ferrite grains in DP steel. In our next report, we will propose the index and techniques and will verify the mechanism for the low punched hole expandability of DP steel proposed in our present report.

\section{REFERENCES}

1) Y. Kuriyama, M. Takahashi and H. Ohashi: J. Soc. Automotive Eng. Jpn., 55 (2001), 51.

2) T. Senuma and M. Takahashi: Materia Jpn., 44 (2005), 488.

3) Y. Tomota, K. Kuroki and I. Tamura: Tetsu-to-Hagané, 61 (1975), 107.
4) Y. Tomota and K. Kuroki: Mater. Sci. Eng., 24 (1976), 85.

5) K. Araki, Y. Takada and K. Nakaoka: Trans. Iron Steel Inst. Jpn., 17 (1977), 710.

6) Y. Tomota and I. Tamura: Tetsu-to-Hagané, 67 (1981), 439.

7) Y. Tomota and I. Tamura: Tetsu-to-Hagané, 68 (1982), 1147.

8) M. Takahashi: Nippon Steel Tech. Rep., 88 (2003), 2.

9) M. Takahashi, O. Kawano, T. Hayashida, R. Okamoto and H. Taniguchi: Nippon Steel Tech. Rep., 88 (2003), 8.

10) M. Mizui, H. Takechi and T. Sekine: Tetsu-to-Hagané, 76 (1990), 414

11) N. Fujita, K. Kusumi, K. Matsumura, T. Nonaka and T. Tomokiyo: Nippon Steel Tech. Rep., 103 (2013), 99.

12) K. Hasegawa, K. Kawamura, T. Urabe and Y. Hosoya: ISIJ Int., 44 (2004), 603.

13) JFS T 1001: 1996, Method of hole expanding test.

14) JIS Z 2256: 2010, Metallic materials-Hole expanding test.

15) ISO 16630: 2009, Metallic materials -Sheet and strip- Hole expanding test.

16) Y. Takahashi, O. Kawano, Y. Tanaka, M. Ohara and K. Ushioda: Tetsu-to-Hagané, 98 (2012), 378.

17) Y. Takahashi, O. Kawano, K. Ushioda and S. Aihara: Tetsu-toHagané, 99 (2013), 312.

18) Y. Takahashi, O. Kawano, K. Ushioda and S. Aihara: Tetsu-toHagané, 99 (2013), 484

19) M. Azuma, S. Goutianos, N. Hansen, G. Winther and X. Huang: Mater. Sci. Technol., 28 (2012), 1092.

20) K. Park, N. Nakada, T. Tsuchiyama and S. Takagi: CAMP-ISIJ, 26 (2013), 400, CD-ROM.

21) A. Sakakibara, T. Matsuno, T. Yokoi and A. Uenishi: CAMP-ISIJ, 26 (2013), 284, CD-ROM.

22) Y. Tanaka, H. Shutoh , T. Yokoi, T. Matsuno and K. Ushioda: CAMP-ISIJ, 27 (2014), 498, CD-ROM.

23) T. Matsuno, D. Maeda, H. Shuto, A. Uenishi and M. Suehiro: ISIJ Int., 54 (2014), 938.

24) F. S. Le Pera: J. Met., 32 (1980), No.3, 38

25) T. Yoshida: J. Jpn. Soc. Technol. Plast., 52 (2011), No.606, 777.

26) Y. Mine, K. Hirashita, H. Takashima, M. Matsuda and K. Takashima: Mater. Sci. Eng. A, 560 (2013), 535.

27) T. Tsuchiya, M. Hirata, N. Chiba, R. Udo, Y. Yoshitomi, T. Ando, K. Sato, K. Takashima, Y. Higo, Y. Satomae, H. Ogawa and K. Ozaki: J. Microelectromech. Syst., 14 (2005), 1178.

28) J. W. Bay, K. J. Handerhan, W. M. Garrison, Jr. and A. W. Thompson: Mater. Trans. A, 23A (1992), 485.

29) M. F. Ashby: Philos. Mag., 21 (1970), 399.

30) H. Kimura, Y. Wang, Y. Akiniwa and K. Tanaka: Trans. Jpn. Soc. Mech. Eng., 71 (2006), 1722.

31) K. Nakashima, Y. Fujimura, H. Matsubayashi, T. Tsuchiyama and S. Takagi: Tetsu-to-Hagané, 93 (2007), 459.

32) V. M. Segal: Severe Plastic Deformation toward Bulk Production of Nanostructured Materials, ed. by B. S. Altan, NOVA Science Publishers, New York, (2005), 1

$33)$ N. Tsuji, Y. Ito, Y. Saito and Y. Minamino: Scr. Mater., 47 (2002), No.12, 893.

34) S. Torizuka, E. Muramatsu, S. V. S. N. Murty and K. Nagai: Scr. Mater., 55 (2006), 751.

35) Y. Okitsu, N. Takata and N. Tsuji: J. Mater. Sci., 43 (2008), 7391.

36) Y. Okitsu, N. Takata and N. Tsuji: Scr. Mater., 60 (2009), 76.

37) I. Tamura, H. Yoshimura, N. Iwasaki and M. Ibaraki: J. Jpn. Inst. Met., 28 (1964), No. 12, 820.

38) I. Tamura and T. Oyama: J. Jpn. Inst. Met., 30 (1966), No. 11, 1081. 